\title{
A Powerful Organocatalytic Methodology for the Synthesis of Spiro-Epoxyoxindoles from Ylideneoxindoles Using tert-Butyl Hydroperoxide
}

\author{
MUKESH KUMAR TYAGI ${ }^{*}$ and SANTOSH KUMAR SRIVASTAVA \\ Department of Chemistry, Dr. H. S. Gour University (A Central University) \\ Sagar-470003(M.P.), India \\ mukeshtyagi57@gmail.com
}

Received 1 January 2016 / Revised 5 June 2016 / Accepted 16 December 2016

\begin{abstract}
Noncovalent organocatalysed epoxidation of ylideneoxindoles is experimentally, theortically and technologically importance. Stereoselective epoxidation for ylideneoxindole cyclohexane-1,3-diones have been successfully designed. Spiro compounds have been formed with two adjacent new stereocentres. The transition state created by H-bonding between bifunctional catalyst and substrate. This procedure is permit to synthesize wide variety of functional groups and gives excellent yields. Furthermore, the bifunctional catalyst could be reused and recovered.
\end{abstract}

Keywords: Ylideneoxindoles, Bifunctional organocatalyst, TBHP, DFT

\section{Introduction}

One of the most functional group in organic chemistry is the epoxy ${ }^{1}$. The epoxy group is highly reactive and has ability to react with nucleophiles to make this function a unique tool for the induction for two adjacent stereogenic centers ${ }^{2}$. Excellent diastereo-, regio-, chemoand enantioselectivity products have been developed ${ }^{3}$. Oxirane has high ring strain and valuable precursors for scope of small molecules and polymers ${ }^{4}$. Spiro-epoxyoxindoles derivatives have been reported to have different kind of skeleton with important biological activities $^{5}$. Isatin ( $1 H$-indole-2,3-dione) derivatives are highly used in the field of medicinal chemistry. There is more demand for new agents associated with mycobacterium tuberculosis (MTB), the causative bacterium of tuberculosis ${ }^{6}$. Some examples of substituted oxiranes have been examined as antitubercular agent ${ }^{7}$. We have focused on the potential of tert-butylhydroperoxide (TBHP) ${ }^{8}$ as an excellent reagent in epoxydation. TBHP is a milder oxidant and a less explosive ${ }^{9}$ than $\mathrm{H}_{2} \mathrm{O}_{2}$.

\section{Experimental}

Melting points were taken in open capillaries tubes. Formation of the compounds were monitored by TLC using silica gel ' $G$ ' and the spots were exposed to iodine vapours and UV 
chamber for visualization. The purification of the synthesized compounds was done by column chromatography. The FT-IR spectra were recorded on $\mathrm{KBr}$ discs in the range of $400-4000 \mathrm{~cm}^{-1}$ with scan rate of 20 per spectrum on a Shimadzu FT-IR $8400 \mathrm{~S}$ instrument. The ${ }^{1} \mathrm{H}$ NMR spectra were recorded on $400 \mathrm{MHz}$ and ${ }^{13} \mathrm{C}$ NMR spectra were recorded on $100 \mathrm{MHz}$ on Bruker Advance-II-400 in DMSO- $\mathrm{d}_{6}$ using TMS as an internal standard on $\delta$ scale. The enantioselectivities were determined by HPLC analysis on chiral stationary phase (TSP spectra series P200, UV detector at $\lambda=254 \mathrm{~nm}$, using Daicel Chiralpack IC column and Daicel Chiralpack IA column). GCMS data with scan rate 709 using C:IGCMS datalinstrument methodLDIPMS in methanol. The reagent grade chemicals were purchased from the commercial sources and purified by either distillation or recrystallization before use.

\section{General method for the synthesis of compounds (entries 1-13)}

We describe herein the organocatalytic epoxidation of ylideneoxindoles (A), which are olefins bearing three electron withdrawing groups at vicinity of the double bond. We have investigated successfully the oxidation to form the spiro (oxirane-oxindole) derivatives (B) and $(\mathrm{C})$ promoted by $(S)$-diphenyl(pyrrolidin-2-yl)methanol derivatives as bifunctional catalysts. (Table 1 , entries $1-13$, Scheme 1 ).<smiles>O=C1Nc2ccccc2C1=C(Cl)Cl</smiles>

(A)<smiles>CCOS(=O)(=O)OCCCCCCC(C)(C)OO</smiles>

(B)<smiles>O=C1O[CH-]C2=Nc3ccccc3C1(O)O2</smiles>

(C)<smiles>O=C1Nc2ccccc2[C@]1(S)OC(Cl)(Cl)Cl</smiles>

(D)

Scheme 1. Synthesis of compounds

Table 1. Epoxidation reactions affect by organocatalyst and solvent

\begin{tabular}{ccccccc}
\hline Entry & Catalyst & Solvent & $\mathrm{mL}$ & Time, $\mathrm{h}$ & ${\text { Yield, } \%^{\mathrm{a}}}^{\mathrm{ee}, \%^{\mathrm{b}}}$ \\
\hline 1 & $\mathrm{P}$ & Hexane & 1.0 & 15 & 92 & 80 \\
2 & $\mathrm{P}$ & $\mathrm{CH}_{3} \mathrm{CN}$ & 0.5 & 180 & 72 & 62 \\
3 & $\mathrm{P}$ & $\mathrm{CHCl}_{3}$ & 0.5 & 175 & 70 & 60 \\
4 & $\mathrm{P}$ & DMSO & 1.5 & 230 & 65 & 65 \\
5 & $\mathrm{P}$ & EtOH & 1.5 & 172 & 62 & 55 \\
6 & $\mathrm{P}$ & Hexane & 0.5 & 12 & 88 & 71 \\
7 & $\mathrm{P}$ & Hexane & 2.5 & 32 & 92 & 82 \\
8 & $\mathrm{P}$ & Hexane & 3.5 & 72 & 85 & 77 \\
9 & $\mathrm{P}$ & Hexane & 2.0 & 24 & 90 & 80 \\
10 & $\mathrm{Q}$ & Hexane & 2.0 & 38 & 82 & 65 \\
11 & $\mathrm{R}$ & Hexane & 2.0 & 72 & 93 & 42 \\
12 & $\mathrm{~S}$ & Hexane & 2.0 & 98 & 88 & 55 \\
13 & $\mathrm{~T}$ & Hexane & 2.0 & 130 & 75 & 70 \\
\hline
\end{tabular}

Bifunctional organocatalyst has chirality which exhibit different outcomes when employed as catalysts P-V (Figure 1 \& Table 2) and initially employed as organocatalysts ( $25 \mathrm{~mol} \%$ ) to promote the epoxidation of an olefin, ylideneoxindole (A). We selected tertbutylhydroperoxide (TBHP) to act an oxidant using hexane as a solvent (Figure 1). 


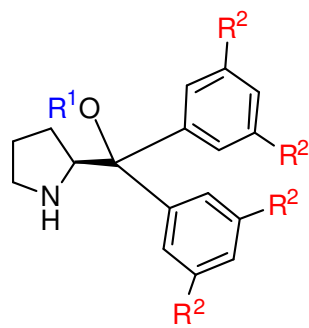

Table 2. Bifunctional organocatalyst

\begin{tabular}{ccc}
\hline Catalyst & $\mathrm{R}^{1}$ & $\mathrm{R}^{2}$ \\
\hline $\mathrm{P}$ & $\mathrm{H}$ & $\mathrm{H}$ \\
$\mathrm{Q}$ & $\mathrm{C}_{2} \mathrm{H}_{5}$ & $\mathrm{CH}_{3}$ \\
$\mathrm{R}$ & ${ }^{\mathrm{B} u}$ & $\mathrm{H}$ \\
$\mathrm{S}$ & $\mathrm{H}$ & $\mathrm{CF}_{3}$ \\
$\mathrm{~T}$ & $\mathrm{H}$ & $\mathrm{CH}_{3}$ \\
\hline
\end{tabular}

Figure 1. Bifunctional catalyst examined with different groups

We have used catalyst $(S)$-diphenyl(pyrrolidin-2-yl)methanol to get the spiro-epoxide with $\mathrm{H}$-bonding (good enantioselectivity $80 \%$ ee, entry 1 ), if we use $\mathrm{CH}_{3} \mathrm{CN}$ as solvent the to produce the spiro-epoxide with less enantioselectivity $(62 \%$ ee, entry 2$)$ because of the solvent polarity. By using more hindered ${ }^{\mathrm{t}} \mathrm{Bu}(S)$-diphenyl(pyrrolidin-2-yl)methanol ${ }^{\circledR}$ (entry 11) it produced decrease enantiomeric excess (ee). Such results provide strong support to take free $\mathrm{OH}$ group in the catalyst which confirm $\mathrm{H}$-bond framework with both the substrate and the reagent. Further evidence, if $\mathrm{CF}_{3}$ group (EWGs) is introducted both aromatic ring of the catalyst which should have to encourage H-bond formation. On this basis different subsequent reaction condition was performed with an inexpensive

$(S)-$ diphenyl(pyrrolidin-2-yl)methanol (P), if more hexane was added, the results were unexpected to stipulate the most favourable enantioselectivity ${ }^{10}$ (entry 7 ).

Developed reaction conditions were obtained by using the parallel ylideneoxindoles $\mathbf{1}(\mathbf{a}-\mathbf{j})$, which were different substitutions at R1, R2 and R3 on the $(S)$-diphenyl(pyrrolidin-2yl)methanol (Scheme 2). These outcomes are concise in Table 3.<smiles>[Z]c1cc([Y])c2c(c1)C(=C(Cl)Cl)C(=O)N2[X]</smiles>

(A)<smiles>CC(C)(C)OO</smiles>

(B)<smiles>[Y]C1=CC(=O)C2(OC2(Cl)Cl)c2cc([Z])cc([Y])c2C12OC2(Cl)Cl</smiles>

(C)<smiles>[Z]c1cc([Y])c2c(c1)[C@@](O)(C(Cl)(Cl)Cl)C(=O)N2[X]</smiles>

(D)

Scheme 2

Table 3. Substrate scope reaction parameters

\begin{tabular}{cccccccc}
\hline Entry & Reagents & $\mathrm{X}$ & $\mathrm{Y}$ & $\mathrm{Z}$ & Time, $\mathrm{h}$ & ${\text { Yield, } \%^{\mathrm{a}}}^{\text {ee, } \%^{\mathrm{b}}}$ \\
\hline 1 & $\mathbf{1 a}$ & $\mathrm{H}$ & $\mathrm{H}$ & $\mathrm{H}$ & 16 & 93 & 85 \\
2 & $\mathbf{1 b}$ & $\mathrm{CH}_{3}$ & $\mathrm{H}$ & $\mathrm{H}$ & 76 & 85 & 80 \\
3 & $\mathbf{1 c}$ & $\mathrm{C}_{6} \mathrm{H}_{5}$ & $\mathrm{H}$ & $\mathrm{H}$ & 42 & 82 & 72 \\
4 & $\mathbf{1 d}$ & $\mathrm{CH}_{3}$ & $\mathrm{H}$ & $\mathrm{F}$ & 20 & 90 & 75 \\
5 & $\mathbf{1 e}$ & $\mathrm{H}$ & $\mathrm{F}$ & $\mathrm{H}$ & 10 & 85 & 65 \\
6 & $\mathbf{1 f}$ & $\mathrm{H}$ & $\mathrm{Cl}$ & $\mathrm{H}$ & 11 & 87 & 72 \\
7 & $\mathbf{1 g}$ & $\mathrm{H}$ & $\mathrm{Br}$ & $\mathrm{H}$ & 14 & 90 & 73 \\
8 & $\mathbf{1 h}$ & $\mathrm{H}$ & $\mathrm{CF}_{3}$ & $\mathrm{H}$ & 6 & 71 & 65 \\
9 & $\mathbf{1 i}$ & $\mathrm{H}$ & $\mathrm{H}$ & $\mathrm{CF}_{3}$ & 13 & 81 & 73 \\
10 & $\mathbf{1 j}$ & $\mathrm{H}$ & $\mathrm{H}$ & $\mathrm{CH}_{3} \mathrm{O}$ & 22 & 91 & 75 \\
\hline
\end{tabular}

The experimental evidences, theoretical calculations and the product obtained could be explained in the Scheme 3 (Reaction mechanism). 


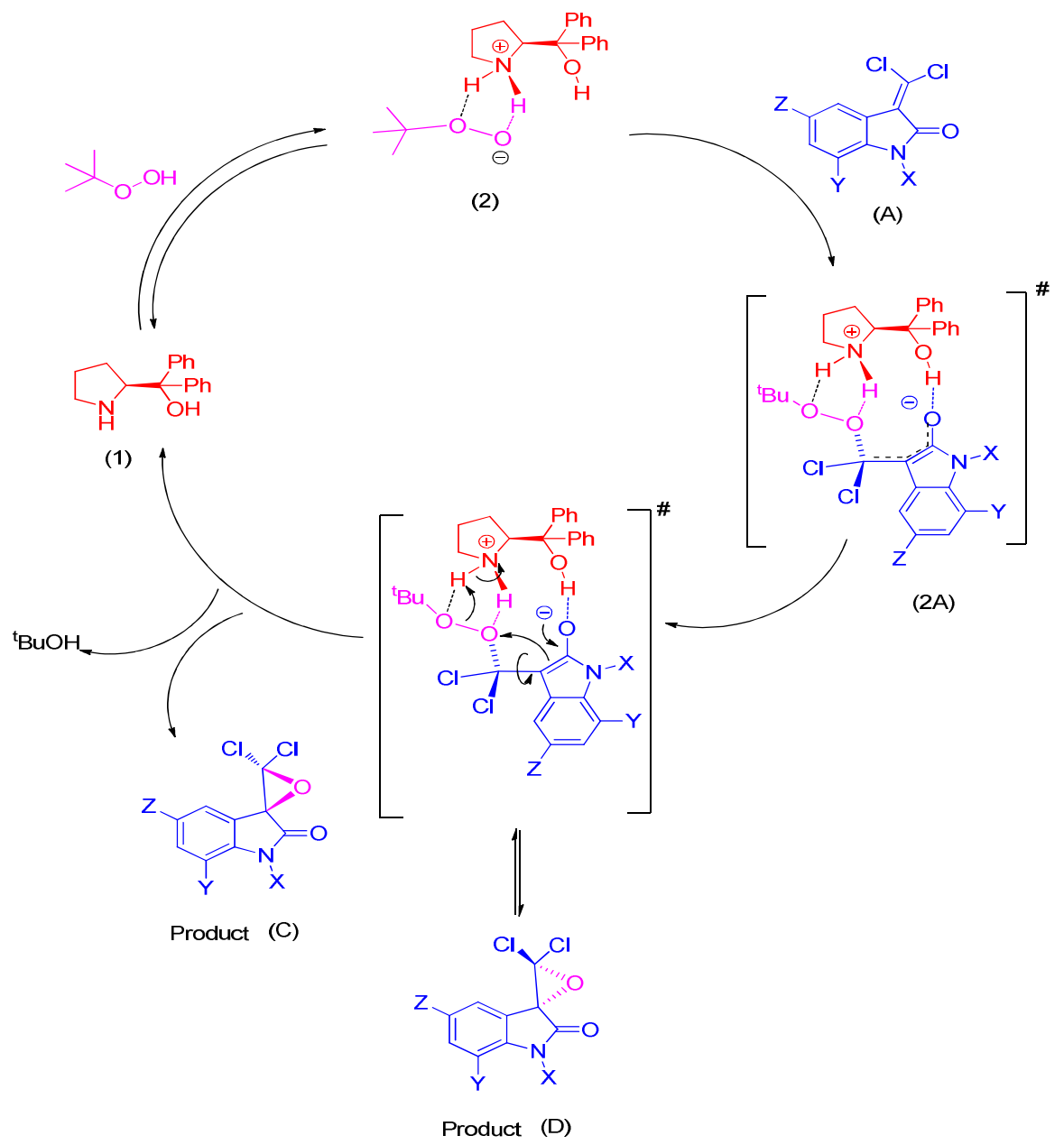

Scheme 3. Reaction mechanism (Postulate mechanism)

\section{Results and Discussion}

We have proposed the following steps of the scheme: (i) the reaction between the catalyst and TBHP and form the tight ion pair 2; (ii) the first nucleophilic attack of 2 on ylideneoxindoles substrate is promoted by both the formation of a stabilizing $\mathrm{H}$-bond between the $\mathrm{OH}$ catalyst and intermediate aromatization; (iii) thus, the substrate and reagent interaction is preferentially toward the less-hindered double bond side, resulting intermediate form and (iv) two products were obtained in the form of oxirane, one is more stable due to H-bonding.

\section{Effect of sodium salt}

We have also used sodium chloride in this reaction. We have observed that sodium salt has to be broken by the H-bonding between the substrate 3',3'-dichloro-1-methylspiro(indoline$3,2^{\prime}$-oxiran)-2-one and catalyst $(S)$-diphenyl(pyrrolidin-2-yl $(0.02 \mathrm{mmol})$ methanol but not observed in the substrate 3',3'-dichlorospiro(indole-3,2'-oxiran)-2-ol substrate (Figure 2). 
<smiles>[Z]c1cc([Y])c2c(c1)C(=C(Cl)Cl)C(=O)N2[X]</smiles>

(A)<smiles>[Z]c1cc([Y])c2c(c1)C(=C(Cl)Cl)C(=O)N2[X]</smiles><smiles>OC(c1ccccc1)(c1ccccc1)C1CCCN1</smiles>

(B)
No Reaction

(A)

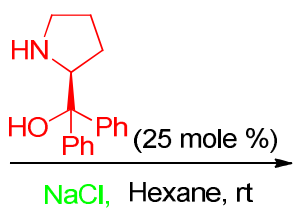

(B)

Figure 2. Effect of $\mathrm{Na}$ salt on the reaction

\section{Computational details}

Now a days DFT calculation has more importance in getting refined results on molecular geometry, electronic properties and optical behavior of systems, in the absence of single crystal XRD data. Possible structure of @-3',3'-dichlorospiro(indole-3,2'-oxiran)-2-ol (with $\mathrm{H}$-bonding) molecule is investigated with $\mathrm{B} 3 \mathrm{LYP} / 6-31^{++} \mathrm{G}$ level ${ }^{11}$. The geometry optimization of these methods yields a 3-D structure as the stable form (Figure 3).

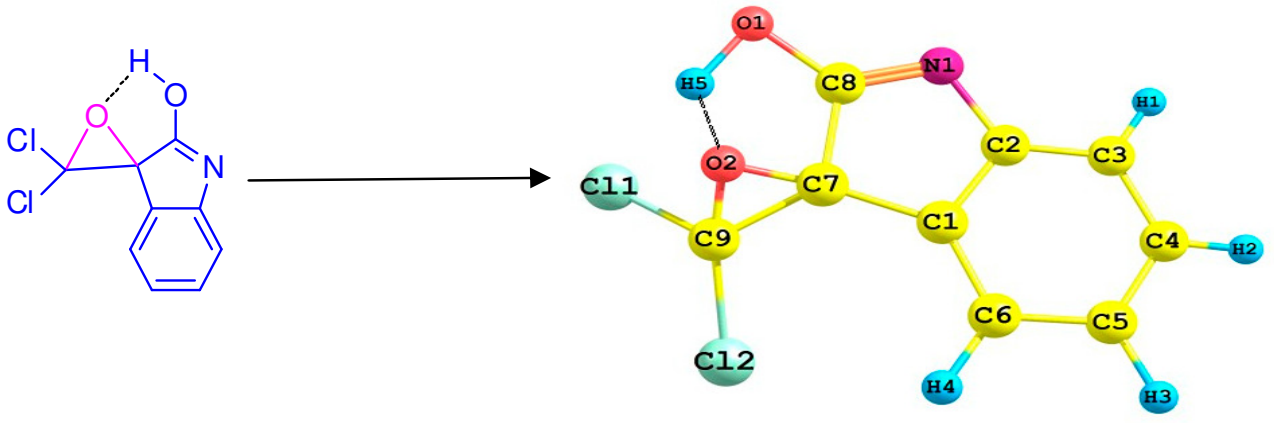

Figure 3. Optimized molecular structural parameters by B3LYP methods with $6-31^{++} \mathrm{G}$ basis set

\section{Conclusion}

The present investigation shows a facile access to highly reactive spiro compounds as potent scaffolds for drug design and it is crucial to understand the geometry or action of the target compound. These compounds have been characterized by FT-IR, ${ }^{1} \mathrm{H}$ NMR, ${ }^{13} \mathrm{C}$ NMR and HRMS. The DFT theory has been successfully employed using B $3 \mathrm{LYP} / 6-31^{++} \mathrm{G}$ basis sets.

\section{Acknowledgment}

One of the authors (MKT) is grateful to UGC, New Delhi to provide the financial assistance in the form of UGC assistantship. We are also thankful to the Head, Department of Chemistry, Dr. Harisingh Gour University (A Central University), Sagar, India for providing 
departmental facilities. We acknowledge the Sophisticated Analytical Instrument Facility (SAIF), Panjab University, Chandigarh, India for spectral and analytical data of the compounds.

\section{References}

1. Palumbo C, Mazzeo G, Mazziotta A, Gambacorta A, Loreto M A Migliorini A, Superchi S, Tofani D and Gasperi T, Org Lett., 2011, 13(23), 6248-6251; DOI:10.1021/ol202646w

2. Suh E M and Kishi Y, J Am Chem Soc., 1994, 116(24), 11205-11206; DOI:10.1021/ja00103a065

3. (a)Hayakawa H, Okada N, Miyazawa M and Miyashita M, Tetrahedron Lett., 1999, 40(24), 4589+4592; DOI:10.1016/S0040-4039(99)00798-4; (b)Calvani F, Crotti P, Gardelli C and Pineeschi M, Tetrahedron, 1994, 50(45), 12999+13022;

DOI:10.1016/S0040-4020(01)81219-9; (c) Smith J G, Synthesis, 1984, 629+656; DOI:10.1055/s-1984-30921

4. (a)McMills M C and Bergmeier S C, InComprehensiveHeterocyclic Chemistry III; Padwa A Ed, Pergamon: Oxford, 2008; (b) Bergmeier S C and Lapinsky D J, In Progress in Heterocyclic Chemistry; Gribble G W and Joule J A Eds, Elsevier Oxford, 2009; (c) Krake S H and Bergmeier S C, Tetrahedron, 2010, 66, 7337-7360. DOI:10.1021/ol402334j

5. (a) Zhu Y G, Wang Q, Cornwall R G and Shi Y A, Chem Rev., 2014, 114(16), 8199256; DOI:10.1021/cr500064w; (b) Boucherif A, Yang Q Q, Wang Q, Chen J R, Lu L Q and Xiao W J J, Org Chem., 2014, 79(9), 3924-3929; DOI:10.1021/jo5003856

6. Klein L, Petukhova V, Wan B, Wang Y, Santasiero B D, Lankin D C, Pauli G F, Franzblau S G, Bioorg Med Chem., 2014, 24, 268-270; DOI:10.1016/j.bmcl.2013.11.024

7. Dandia A, Singh R, Saha M and Shivpuri A, Pharmazie., 2002, 57, 602; DOI:10.1016/j.ultsonch.2010.12.010

8. Estevesa H, Fátimab Â D, Castroc R P, Sabinoc J R, Macedo Jr F and Brito T O, Tetrahedron Lett., 2015, 10, 88; DOI:10.1016/j.tetlet.2015.10.088

9. Fieser M, Danheiser R L, Roush W, Sharpless K B and Verhoeven T R, Aldrichimica Acta, 1979, 12, 63-74.

10. Weiss K M and Tsogoeva S B, Chem Rec., 2011, 11, 18; DOI:10.1002/tcr.201000006

11. Wang H, Meng X, Fan C and Fan Y B C, J Mol Str., 2016, 1107, 25-30;

DOI:10.1016/j.molstruc.2015.11.035 